\title{
Creative Focus as Resource Mechanism for Activity Style of Sales Manager
}

\author{
Shapovalov V.I. \\ Sochi State University, \\ Sochi, Russia \\ shapovalov_vi@mail.ru
}

\author{
Shuvanov I.B. \\ Sochi State University, \\ Sochi, Russia, \\ shapovalov_vi@mail.ru
}

\author{
Shuvanova V.P. \\ Sochi State University, \\ Sochi, Russia, \\ shapovalov_vi@mail.ru
}

\begin{abstract}
Association of a creative potential of a sales manager's personality with structural components of their activity style is revealed. It is noted that a creative component of a manager is the most important one among various factors determining the effective style of activity. Creative focus is regarded as a resource mechanism for implementing the style of activity of a manager. The reverse process is also considered: the impact of choice of different activity styles on the use of the resource of a manager's creative potential. This means that the problem is posed as follows: whether a regulative component (choice of the style of activity) can influence the development of a cognitive component (latent creative potential). The research program includes three stages. The first stage is to study a creative potential of the sales manager's personality according to five units of parameters (motivational, creative, professional, personal, social), which altogether represent the creative potential index. The second stage is to study the style of activity based on a model developed by the authors which includes a mathematical description of the index of the style of activity as a systemic parameter whose value simultaneously takes into account two focuses in the manager's activities (both on the result and the client). The third stage is to reveal associations of structural components of the manager's style of activity with their creative potential. The association of a creative potential of the manager with their arbitrary choice of one of the directions of the activity style is demonstrated. In the system of two interacting processes (regulatory and cognitive), creativity plays the role of a resource mechanism that optimizes the manager's style of activity.
\end{abstract}

Keywords-creativity resource, activity style, sales manager, creativity index, activity style index, synergism

\section{INTRODUCTION}

In modern Russia the social and economic situation requires the new qualities from the manager. A new management competence associated with the ability of a manager to select the most effective activity style, considering internal and external conditions in frequently unpredictable circumstances, has become especially significant. Under these conditions, the manager needs the ability to skillfully use their creativity as well as the ability to implement this creativity in daily activities, in order to be professionally competitive. Competent use of one's creativity as a resource mechanism for an arbitrary choice of any activity style in the context of determinism principle involves considering a person's behavior as a result of influence of a variety of external and internal factors. In our opinion, the creativity of the manager is the most important factor in selecting an activity style. In fact, a person's creativity plays the role of ensuring the choice of the most adequate style of activity in a particular situation, which results in achieving the planned professional goal [1]. On the other hand, we may assume the opposite: the impact of the activity style on the use of the creative resource of the manager [2, 3]. Thus, Parker [4] noted that a more creative individual sometimes cannot achieve better competitiveness in their activities, if this individual cannot use their resource, selecting a style strategy. Representatives of humanistic psychology [5, 6] call the process of revealing one's potential resource with its subsequent realization self-actualization, realization of one's capabilities, personal growth, etc. According to humanistic psychology, the personal potential is an innate feature of any person's mentality, and the degree of revealing this potential varies depending on a person's professional maturity.

Such reasoning is close to the concept of "the manager's competitiveness". Competitiveness determines the ability of an individual to use their psychological resource, overcoming, for example, fear and uncertainty to achieve a goal. In this way, creativity as an innate psychological component of the personality, and, especially, the level of revealing one's resource when choosing an activity style, acts as the mechanism lowering the limitation of potential creative competitive abilities [7], i.e. the mechanism increasing the 
competitiveness of the manager's professional activities in general. So, a conscious creative resource is a feature of creativity. A conscious creative resource allows the manager to select different activity styles within their psychological potential. If the assessment of the resource used is lower than that of the actual one, then the successful activities and, consequently, the competitiveness can be questioned. We have the right to assume that a creative potential can possess creative resources that are different by quantity and quality, depending on the degree of what how conscious they are and how skillfully they are used.

The reverse process is also of interest: the influence of choosing different activity styles on the use of the resource of the manager's creative potential. That is, the question is put as follows: whether a regulative component, the choice of an activity style, can influence the revealing of a cognitive component, a latent resource of the potential of creative competitive abilities. The theoretical assumption is that the style of activity is a way of realizing a creative potential of the manager. The division of the style of activity into components (directed towards business or an individual) [8] is determined by limited possibilities of the available creative potential (capabilities) of a manager in organizing the systemic functioning of two orientations according to the synergism principle.

Hence, one should expect:

- association of a high level of an integral parameter of the manager's style of activity with a high level of realizing a creative potential;

- decrease of both the level of an integral parameter of the manager's style of activity and specific correlations between the style of activity and parameters of their creative potential provided that the style of activity is directed towards either business or a person.

\section{PROBLEM STATEMENT}

Despite the focus on creativity creative orientation [9-11] and the style of activities [12-16], there are practically no investigations of the relationship between these two indicators of a manager's personality. Nowadays, the undisputable fact is that the management efficacy depends directly on creative solutions of management problems.

The manager's activities take place in the conditions of a quickly changing situation, when it is required to analyze a great amount of information and, on this base, make an adequate management decision [17]. Due to these circumstances, the manager is, in fact, a creative organizer of production relationships in the "manager-employeer" system based on the manager's personal creative potential. Thus, new requirements imposed on the manager's personality and their effective functioning demand the study of relationships between the manager's creative potential and their style of activity.

\section{RESEARCH PROBLEMS}

- To study the resource of creative potential as the mechanism of choosing an optimal style of the manager's activities.
- To reveal the influence of realizing different styles of activities on the use of the manager's creativity resource.

\section{RESEARCH PURPOSE}

To determine the relationships of the manager's personal creativity potential with structural components of their style of activity.

\section{RESEARCH METHODS}

\section{A. Rationale for the choice of the research participants.}

Sales manager is a seller, intermediary between the producer and the consumer of goods. Their main task is not only to master the range of communicative PR - technologies necessary for successful sales but also foresee the future demand for goods [18-20]. Consequently, the sales manager realizes practically the set of qualities which directly personify, first of all, such creative abilities as readiness for non-standard decisions, flexibility of thinking, ability to generate the variety of ideas, ability to risk, etc.

\section{B. Methods and procedure of creativity orientation research}

Theoretical prerequisites for an empiric research are the following approaches to understanding a manager's creative orientation as the most important resource mechanism for choosing the style of activity:

- relations between a creative potential and the manager's style of activity "have two-sided nature: on the one hand, the style is a result of creative activity, on the other hand, the process of choosing and adopting a definite style is a generating source of creativity and its development" [16];

- the style of activity is a way to implement the potential resource of a creative person in activity [15];

- the style of activity acts as the mechanism of integrating different levels of one's creative potential, and as the most important condition for one's personal development [15];

- thanks to the style of activity a person can consciously or spontaneously use and develop his creative potential in the best way [3].

The first stage: selection and adaptation of methods for studying the creative potential of the personality of a sales manager. The analysis of various literary sources allowed distinguishing 29 indicators significant for implementing the creative potential of a sales manager, these are united into five units: I. Motivational; II. Creative; III. Professional; IV. Personal; V. Social. Altogether these components of the creative orientation represent the index of the creative potential (ICP).

The second stage: selection and adaptation of methods for studying the style of activity of a sales manager. When organizing a system of management relations with a client, a sales manager solves two problems: (1) to get a planned profit and (2) to satisfy the client. Two styles of activity correspond to these two management problems: (1) predominantly resultsoriented management, and (2) the client' personality oriented management. Using this approach, it is possible to 
classify the work of a sales manager by types of activity styles:

Type 1 - the manager seeking to increase the effectiveness of interaction in the "manager-client" system due to "hard" (administrative) methods of interaction with the client (authoritarian impact);

Type 2 - the manager seeking to increase the interaction effectiveness in the "manager-client" system due to "soft" (democratic) methods and approaches acting on the personality of a client;

Type 3 - the effective manager seeking to optimize the interaction quality in the "manager - client" system due to the synergetic effect from the reasonable use of "hard" and "soft" methods of impact on a client;

Type 4 - the manager focused on the natural course of the manager-client interaction process.

Thus, according to the systemic approach [21], the main indicators of the activity style include: (1) the manager's focus on results (FR); (2) the focus on the communication subject the client (FC); as well as (3) the integral indicator, the index of the manager's activity style (IMAS), characterizing the synergic effect from the use of various combinations of two style focuses. IMAS is calculated by the formula (1):

$$
I M A S=(1,41 \times X \times Y) /(X+Y)
$$

where:

$X$ - the manager's focus on results (FR);

$Y$ - the focus on the communication subject, the client (FC);

$I M A S$ - the index of the manager's activity style [7].

Methods for evaluating the manager's activity style have been selected and adopted for the research purposes. The adaptation was carried out on the basis of theoretical and empiric analysis of the sales manager's activities, the analysis of literary sources on the problem under consideration, as well as the above classification of the types of the manager's activity.

The third stage: identification of the association between structural components of the manager's activity style and their creative potential. After processing the empiric data and calculating the correlation coefficients the analysis was carried out to confirm or reject the assumptions about the association between creativity and efficiency of the manager's activity style.

\section{RESULTS AND DISCUSSION}

Identification of the association between creativity and efficiency of the sales manager's activity style. Table I represents the results of assessment of the manager's focus on the results (FR) and the client (FC), as well as calculated values of the generalized index of the manager's activity style (IMAS) and the index of the creative potential (ICP).

Tab. 1 shows that the average value of the sales manager's activity style is characterized by the focus on the result (9.64). This value is higher than the focus on the client (6.40). IMAS of an average manager has the level - 3.52. In fact it means that if the manager has a sufficiently high focus on the result, then due to the low focus on the client, their integral indicator of the activity style decreases (in our case to 3.52). When communicating with the client, the manager of this kind prefers "hard" interaction methods, mainly with a focus on getting a profitable result for themselves. The main results in business communication with a client can be achieved predominantly through rational, administrative and command methods of interpersonal management. At the same time the resource of the manager's creativity remains unclaimed, though it could certainly contribute to the search for more effective interaction mechanisms, taking into account the characteristics of the client's personal factor.

TABLE I. RESUlTS OF THE ASSESSMENT OF THE MANAGER'S ACTIVITY STYLE AND CREATIVITY

\begin{tabular}{|c|c|c|c|c|}
\hline & FR & FC & IMAS & ICP \\
\hline 1 & 3.20 & 11.40 & 3.52 & 3.23 \\
\hline 2 & 12.80 & 5.70 & 5.56 & 4.64 \\
\hline 3 & 13.10 & 2.60 & 3.06 & 3.94 \\
\hline 4 & 6.30 & 2.50 & 2.52 & 3.88 \\
\hline 5 & 8.30 & 4.70 & 4.23 & 4.43 \\
\hline 6 & 13.10 & 6.50 & 6.13 & 4.05 \\
\hline 7 & 8.70 & 14.30 & 7.63 & 5.34 \\
\hline 8 & 6.75 & 10.60 & 5.81 & 4.85 \\
\hline 9 & 9.70 & 9.40 & 6.73 & 4.06 \\
\hline 10 & 11.70 & 3.80 & 4.04 & 4.03 \\
\hline 11 & 14.20 & 2.30 & 2.79 & 4.00 \\
\hline 12 & 4.10 & 6.30 & 3.50 & 3.87 \\
\hline 13 & 3.10 & 5.70 & 2.83 & 3.67 \\
\hline 14 & 6.00 & 11.40 & 5.54 & 4.12 \\
\hline 15 & 9.77 & 5.40 & 4.90 & 3.89 \\
\hline 16 & 12.30 & 3.10 & 3.49 & 3.40 \\
\hline 17 & 6.50 & 5.21 & 4.03 & 4.14 \\
\hline 18 & 12.20 & 6.40 & 5.92 & 4.20 \\
\hline 19 & 4.60 & 6.47 & 3.91 & 3.12 \\
\hline 20 & 12.80 & 4.40 & 4.62 & 4.56 \\
\hline Av.values & 9.64 & 6.40 & 3.52 & 4.09 \\
\hline Deg.of dev. & 4.09 & 3.41 & 1.69 & 0.51 \\
\hline
\end{tabular}

The association between the manager's creativity and different types of activity style was studied using Spearman rank correlation coefficient [22] (Table II).

TABLE II.

VALUES OF CORRELATION COEFFICIENTS

\begin{tabular}{|c|c|c|c|}
\hline & IMAS & FR & FC \\
\hline ICP & 0.649 & 0.302 & 0.335 \\
\hline
\end{tabular}

From the table it follows:

- the presence of the evident connection between the IMAS and the manager's creative potential - 0.649 (by Chaddok's criterion) [22]; 
- the presence of moderate connection between the manager's focus on results (FR) and the realization of the creative potential equal to -0.302 ;

- the presence of the moderate connection between the manager's focus on the client (FC) and the realization of the creative potential -0.335 .

Thus, the first assumption made in the work is confirmed. In fact, the realization of creativity is associated with the effectiveness of the style of activity. At the same time, individual orientations (towards the result and towards the client) do not have a marked association with the level of creativity realization.

Identification of influence of realization of different activity styles on the use of creativity resource of the manager. The following aspect of the analysis is to test the assumption that a spontaneously changing activity style provides different realization of creativity of the manager. This means that the inherently regulatory process of choosing an effective activity style necessarily leads the manager to changes in the cognitive sphere - the realization of a definite resource of their creativity.

To test the assumptions made, the following actions were realized:

- the values of the indices of activity styles (IMAS) and its components (FR and FC) were distributed by levels: high, medium and low;

- the groups of tested subjects were identified which had high and low levels by the FR, FC and IMAS indicators:

- the average values of creativity indicators were calculated for each group;

- Mann-Whitney U-test was applied to prove the association between the activity style and the realization of the manager's creative potential [22].

This criterion shows the reliability of the differences in the average values in both groups. In our case, we determine the reliability of the differences in the average values:

- between the creativity levels for subjects with high and low values of focus on the result;

- between the levels of creative potential for subjects with high and low values of focus on the client;

- between the levels of creative potential for subjects with high and low values of IMAS.

As a result:

- significant differences in the indicator of creative potential for two groups of subjects with high and low values of focus of the activity style on the result were not identified, i.e. the activity style focus exceptionally on the result does not require significant changes in the creative potential realization;

- significant differences in the indicator of creative potential for two groups of subjects with high and low values of focus on the client were not identified, i.e. the activity style focus exceptionally on the client does not require the involvement of additional resources of personal creativity;

- a significant difference in the indicator of creative potential for two groups of subjects with high and low levels of IMAS was identified, i.e. the manager's desire to simultaneously use two focuses (on the result and on the client) in order to increase the effectiveness of the activity style requires them to attract and reveal the creative potential resource in a different way. If the manager strives to achieve an effective activity style with equally high focuses on the result and on the client, then this effectiveness provides a higher level of their creativity realization.

\section{CONCLUSION}

The used approach allowed us to visually illustrate the association of a regulatory component of the manager's personality (an arbitrary choice of one of the focuses of activity style: authoritarian, democratic, optimal) with a cognitive component of the personality - creativity. Creativity in the system of two interacting processes (regulatory and cognitive) plays the role of a resource mechanism which optimizes the sales manager's style of activity.

Alongside this, the theoretical assumption that the style of activity is a way to realize potential creative possibilities of a manager was confirmed. The division of the style of activity into components (the focus either on the result or the client) is determined by limited possibilities of available creativity of a manager in organizing the systemic functioning of two focuses (on business and on a person) according to the synergism principle. So, on the whole the existence of association between the characteristics of the manager's style of activity and their creativity has been proven.

\section{References}

[1] T. Santalainen, E. Voutilainen, P. Porenne, and H.J. Nissinen, "Management by Results", Moscow: Progress, 1993.

[2] T.N. Golovanova, and M.V. Belova, "Investigation of relationship between management style and orientation of employees' personality", Bulletin of the Mari State University, 2017, vol. 3(27), pp. 55-61. (in Russ.).

[3] E.A. Klimov, "Engineering Psychology and Ergonomics" Yurayt Publishing House, Moscow, 2020. (in Russ.).

[4] G.A. Parker, "Assessment strategy and the evolution of fighting behavior", Journal of Theoretical Biology, vol. 47(1), pp. 223-243.

[5] A.G. Maslow, "Far limits of human psyche", Piter, Saint-Petersburg, 2019. (in Russ.).

[6] K. Rogers, "Group psychotherapy", Moscow: Institute of General Humanitarian Research, Moscow, 2017. (in Russ.).

[7] V. Shapovalov, I. Shuvanov, and V. Shuvanova, "System approach to the research of the competitive strength of managerial personnel", The European Proceedings of Social \& Behavioural Sciences (EpSBS), 2018, pp. 843-854. (in Russ.). DOI: https://doi.org/10.15405/epsbs.2019.04.91

[8] I.B. Shuvanov, and V.I. Shapovalov, "Cascade assessment of professional competence. Druzhinin readings", Collection of materials of the XV All-Russian scientific and practical conference, 2016, pp. 2331. (in Russ.). Retrieved from https://elibrary.ru/item.asp?id=28055716

[9] R. Reiter-Palmon, "Team creativity and innovation", Oxford University Press, 2017.

[10] E.M. Akishina, and E.N. Piryazeva, "Contemporary digital art as a factor in the creative development of personality", European Proceedings of Social and Behavioural Sciences EpSBS, 2019, pp. 18-24. (in Russ.). DOI: https://doi.org/10.15405/epsbs.2019.09.02.3 
[11] A.E. Voiskounsky, T.D. Yermolova, V.M. Khromova, and S.R Yagolkovskiy, "Creativity in online gaming: individual and dyadic performance in minecraft", Psychology in Russia: State of the art, vol. 10(4), pp. 144-161. (in Russ.).

[12] D.Zh. Abilmazhinova, "Leadership style as a factor of its effectiveness", New science: Experience, tradition, innovation, vol. 10(1), pp. 3-6. (in Russ.).

[13] M. Armstrong, and S. Taylor, "Human resource management practice", Saint-Petersburg: Piter, Progress kniga, 2018. (in Russ.).

[14] T.N. Dukhina, "The problem of choosing leadership styles in a management culture: A theoretical analysis", Historical and socioeducational thought, 2016, vol. (1)2, pp. 140-144. (in Russ.)

[15] V.S. Merlin, "Psychology of individuality: Selected psychological works", Moscow: Publishing House of the Moscow Psychological and Social Institute, 2009. (in Russ.).

[16] P.K. Khurmatullina, "The content of the individual creative style of pedagogical activity". Kazan pedagogical journal, 2019, vol. 2, pp. 161164. (in Russ.).
[17] A. Alzyoud, "The influence of human resource management practices on employee work engagement", Foundations of Management, 2018, vol. 10(1), pp. 251-256. DOI: https://doi.org/10.2478/fman-2018-0019

[18] J.H. Oh, "A conceptual framework for successful salesperson role change management", Journal of Business \& Industrial Marketing, vol. 32(8), pp. 1136-1143. DOI: https://doi.org/10.1108/JBIM-07-2016-0163

[19] S. Echchakoui, "Effect of salesperson personality on sales performance from the customer's perspective: Application of socioanalytic theory", European Journal of Marketing, 2017, vol. 51(9/10), pp. 1739-1767. DOI: https://doi.org/10.1108/EJM-03-2016-0147

[20] S. Alavi, J. Habel, P. Guenzi, and J. Wieseke, "The Role of leadership in salespeople's price negotiation behavior", Journal of the Academy of Marketing Science, 2018, vol. 46, pp. 703-724. DOI: https://doi.org/10.1007/s11747-017-0566-1

[21] M. Meckon, M. Albert, and F. Hedouri, Fundamentals of management. Classic edition. Moscow: Williams, 2020. (in Russ.).

[22] H.T. Tokunaga, "Fundamental Statistics for the Social and Behavioral Sciences", San Jose State University, USA, 2018. 